\title{
MODALITIES FOR DETECTION OF LV DYSFUNCTION
}

\author{
A.N. Patnaik, Johann Christopher
}

\begin{abstract}
:
The left ventricular ejection fraction (LVEF) assessed by transthoracic Echocardiogram (TTE) remains the most common parameter of $L V$ performance that is used in clinical practice. Three-dimensional / volumetric methods are more accurate, but are cumbersome to be performed in every case. The measures of myocardial contractility are more sensitive, reliable and with lesser inter observer variability but their place in daily practice is limited. Two-dimensional echocardiogram has the advantages of easy availability, low cost, portability, lack of radiation and non-invasive nature. Radionuclide studies, SPECT, cardiac CT and cardiac MRI are available only in a few centers and have more specific indication to be performed. The choice of a modality depends on the information sought by the clinician and the availability of expertise. Additional cost, radiation and limited access are important limitations of these special imaging modalities. The invasive methods which were popular a few decades back are by and large relegated to academic exercise.

Key-words: LV function, Ejection fraction, Echocardiography, Cardiac CT, Cardiac MRI
\end{abstract}

\section{INTRODUCTION}

The functional status of left ventricle (LV) is the main criterion in deciding a management-strategy for many cardiac diseases. Clinical assessment of LV function is far from being precise and hence we need to depend on one, two or multiple parameters obtained by one or more modalities. The disease prognostication management algorithm, follow up, decisions with regard to surgery, catheter based procedures, CRT for heart failure, cancer chemotherapy and need for stop or modify medications and many such issues can all depend on the state of LV function. With growth of concepts like isolated systolic, diastolic or combined ventricular dysfunction, heart failure with preserved or reduced ejection fraction, the science and art of assessment of LV function is becoming complex, confusing and at times controversial as well.

Article received on 10 OCT 2016, published on 31 OCT 2016.

A.N.Patnaik ${ }^{1}$, Johann Christopher ${ }^{2}$

${ }^{1}$ Sr. Consultant, Cardiology, STAR Hospitals, Hyderabad, India

${ }^{2}$ Consultant, Cardiology, CARE Hospitals, Banjara Hills, Hyderabad

Corresponding author: A.N.Patnaik

Email: anpatnaik@yahoo.com

\section{Available Modalities}

The common modalities which can be used for assessment of LV function and their advantages, disadvantages and potential role are summarized in Table-1. The choice of modality depends on the issue that needs to be addressed, availability, portability, expertise, non-invasiveness, radiation safety, use of contrast agent and patient affordability. On most scores the trans-thoracic echocardiogram stands out as a first choice.

\section{Echocardiography and Doppler Studies}

The principles of echocardiography and various modes of examination can be found in any of the several standard text books and are not reviewed here. The parameters of LV function are aimed at knowing either systolic or diastolic performance as detailed in Table- 2 . The 2D images derived from transthoracic studies (2DTTE) are invariably used at most centers for the initial evaluation of LV function. TTE is readily available, noninvasive, safe, low cost, portable, may repeated any number of times. Due to absence of radiation it is safe in the pregnant women. In emergent situations like shock or LVF, it is the best modality for quick assessment and most suited in critical patients on monitors, ventilator and multiple support systems. The main limitations are poor acoustic windows in some patients and operator dependence. However, intra and inter observer variability from 15 to $18 \%$ has been observed with $2 \mathrm{D}$ TTE-LVEF [1].

Global systolic function is often measured by ejection fraction (EF) or fractional shortening (FS) as shown in Fig 1 and Fig 2. It is estimated quantitatively or qualitatively, when it is described as normal, hyperdynamic or depressed. Depressed LV function can be global or regional and is further expressed as mild (EF- 41-51 for men; 41-53 for women), moderate (30-40) and severe $(<30)$ as suggested by American society of echocardiography. 2D echo-derived LVEF has been validated to be fairly accurate compared to radionuclide or invasive ventriculogram derived EF $[2,3]$. 
Table 1: Different modalities available for detection of LV dysfunction.

\begin{tabular}{|c|c|c|c|}
\hline $\begin{array}{l}\text { Modality of } \\
\text { investigation }\end{array}$ & Advantages & Disadvantages & Remarks \\
\hline $\begin{array}{l}\text { Echo and } \\
\text { Doppler } \\
\text { parameters }\end{array}$ & $\begin{array}{l}\text { Non-invasive } \\
\text { Widely available } \\
\text { Portability } \\
\text { Inexpensive } \\
\text { Repeatability } \\
\text { Safe to the patient in general and in } \\
\text { pregnancy } \\
\text { No radiation } \\
\text { Well suited to critically ill patients } \\
\text { on several monitors and supports }\end{array}$ & $\begin{array}{l}\text { Operator dependent } \\
\text { Needs adequate windows } \\
\text { reliance on geometrical } \\
\text { assumptions; } \\
\text { less accurate when LV is of } \\
\text { abnormal shape or if gross RWMA }\end{array}$ & $\begin{array}{l}\text { Most user friendly } \\
\text { and popular }\end{array}$ \\
\hline $\begin{array}{l}\text { Invasive } \\
\text { Catheterization } \\
\text { methods }\end{array}$ & Considered a gold standard & $\begin{array}{l}\text { Invasive in nature } \\
\text { Use of iodinated contrast media } \\
\text { Ionizing radiation } \\
\text { Not widely available } \\
\text { Needs special expertise }\end{array}$ & Good teaching tool \\
\hline $\begin{array}{l}\text { Radionuclide } \\
\text { methods }\end{array}$ & No geometric assumptions & $\begin{array}{l}\text { Needs special expertise } \\
\text { Not portable } \\
\text { expensive } \\
\text { not widely available } \\
\text { Ionizing radiation }\end{array}$ & $\begin{array}{l}\text { Good tool in larger } \\
\text { hospitals }\end{array}$ \\
\hline SPECT-MPI & Excellent information & $\begin{array}{l}\text { Not widely available } \\
\text { Needs special expertise } \\
\text { Not portable } \\
\text { expensive } \\
\text { Ionizing radiation }\end{array}$ & $\begin{array}{l}\text { Good tool in larger } \\
\text { hospitals }\end{array}$ \\
\hline Cardiac CT & Good anatomic details & $\begin{array}{l}\text { Not widely available } \\
\text { Needs special expertise } \\
\text { Not portable } \\
\text { expensive } \\
\text { Ionizing radiation } \\
\text { Use of iodinated contrast media }\end{array}$ & $\begin{array}{l}\text { Good tool in larger } \\
\text { hospitals }\end{array}$ \\
\hline CMR & $\begin{array}{l}\text { No ionizing radiation } \\
\text { Excellent anatomic details }\end{array}$ & $\begin{array}{l}\text { Not widely available } \\
\text { Needs special expertise } \\
\text { Not portable } \\
\text { expensive }\end{array}$ & $\begin{array}{l}\text { Becoming more } \\
\text { popular for the } \\
\text { comprehensive } \\
\text { information that can } \\
\text { be obtained }\end{array}$ \\
\hline
\end{tabular}


Table 2: Echo parameters and its relevance.

\begin{tabular}{|c|c|c|}
\hline Item & Parameter & Issue addressed \\
\hline $\begin{array}{l}\text { Systolic } \\
\text { function }\end{array}$ & $\begin{array}{l}\text { A. Regional wall motion abnormalities } \\
\text { B. Global systolic function } \\
\text { LV dimensions in systole and diastole } \\
\text { Ejection fraction } \\
\text { Fractional shortening } \\
\text { LV volumes } \\
\text { Mitral regurgitation } \\
\text { Systolic wall thickening } \\
\text { LV mass }\end{array}$ & $\begin{array}{l}\text { Coronary artery disease } \\
\text { Systolic heart failure } \\
\text { assessment }\end{array}$ \\
\hline $\begin{array}{l}\text { Diastolic } \\
\text { function }\end{array}$ & 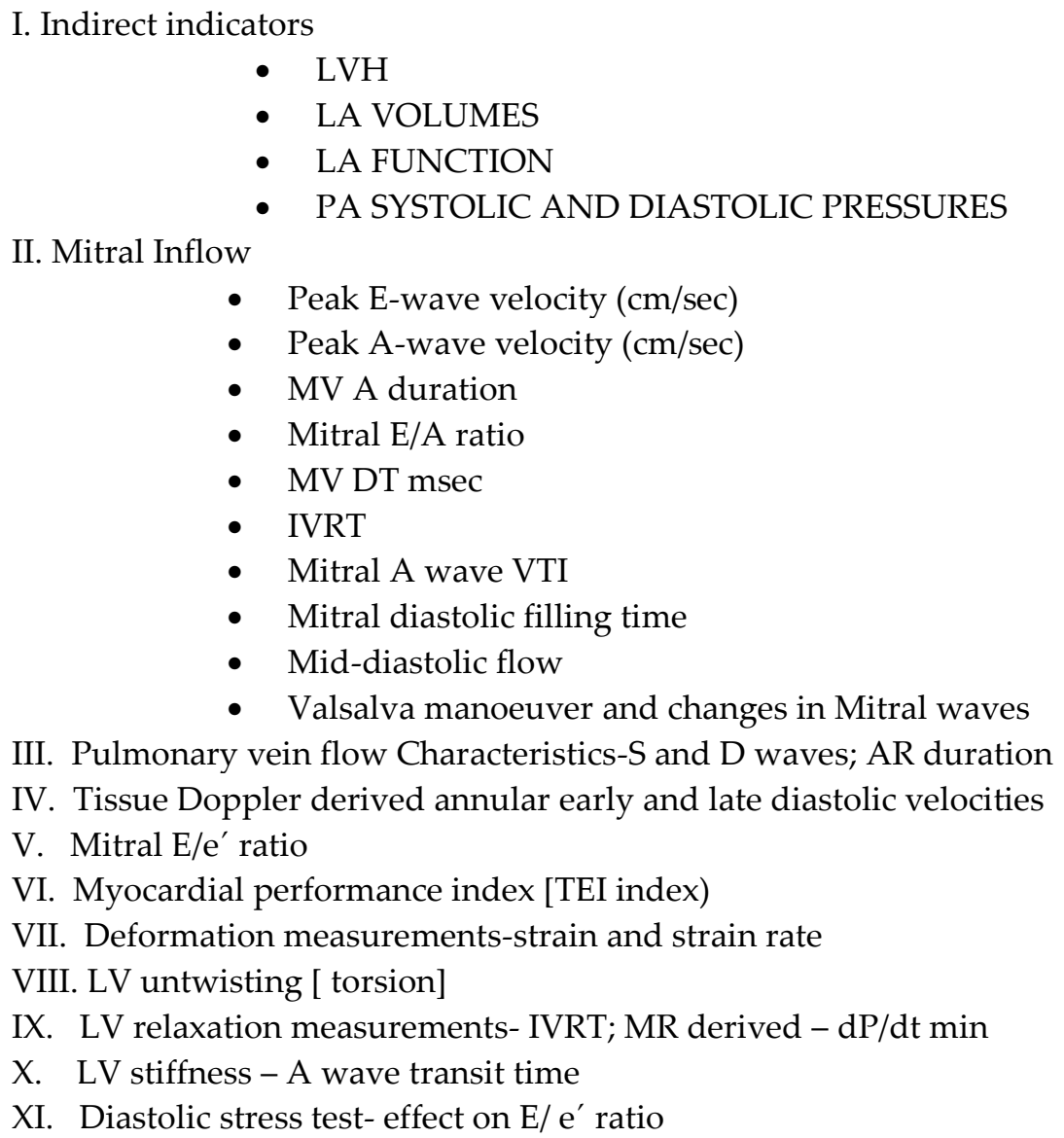 & $\begin{array}{l}\text { Hypertensive heart disease } \\
\text { Heart failure evaluation }\end{array}$ \\
\hline
\end{tabular}

An accurate estimate of the left ventricular systolic and diastolic volumes is an equally important parameter for precise decision making in the management of several conditions. However, the volume measurements are more operator- dependent and are subject to errors due to transducer alignment and foreshortening of views. Besides the use of harmonic imaging, the endocardial border delineation can be improved by use of ultrasonic contrast media which have a few contraindications and are not recommended in pregnancy. The intra and interobserver variability is lesser than conventional methods [4]. For the purpose of regional wall abnormality evaluation, a 16-segment model is suggested by ASE in which absence of systolic thickening, thinning or stretching are visually assessed. A semi qualitative score is calculated in each segment by assigning normal / hyperkinetic $=1$; hypokinetic $=2$; akinetic $=3$; dyskinetic $=4$ and the sum of it taken as total score [5]. 
Fig 1: M-mode echocardiography (parasternal long-axis view, calculation of $\mathrm{LV}$ volumes and ejection fraction by Teichholz method) in normal patient (A) and patient with severe LV dysfunction (B).
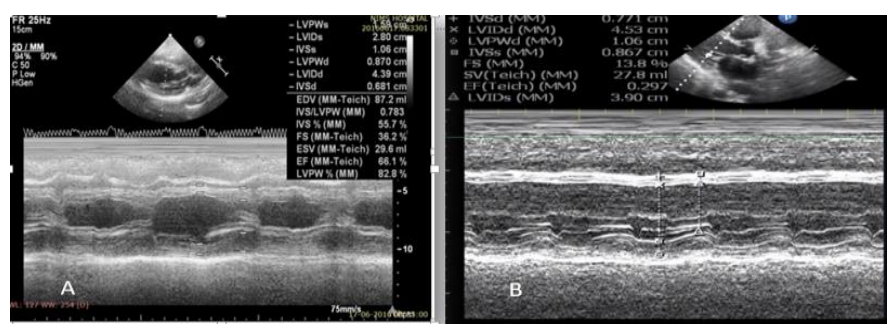

Fig 2: The biplane method of disks (modified Simpson's rule) in apical 4-chamber view for determination of the ejection fraction in a normal patient (A) and in patient with severe LV dysfunction (B).

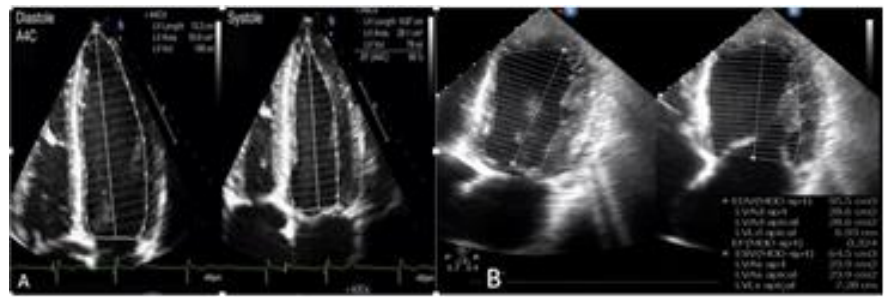

It is more difficult to measure myocardial contractility, which is conventionally measured by calculating the rate of pressure rise in $\mathrm{LV}$ during systole with time $(\mathrm{dP} / \mathrm{dt})$ from the Doppler spectrum across the mitral valve [6]. Myocardial velocities, strain and strain rate, myocardial velocity gradient are good parameters for assessment of intrinsic contractile function but are not been adopted into routine daily practice; they remain tools for research. It is now accepted that global longitudinal strain may be a better alternative to EF being more sensitive and can be used for prognostication [7].

The study of diastolic function as a concept grew over years and is now a routine practice in most laboratories. It is of vital importance in any patient presenting with dyspnea or heart failure. The diastolic dysfunction can be assessed from the Doppler spectrum across mitral valve, Pulmonary vein and tissue velocities from the septal and lateral walls as shown Fig 3 and Fig 4. The primary parameters included measurement of IVRT, E/A ratio, DT, A duration, PV S/D ratio, PV AR velocity, PV AR duration, septal e', Septal e'/a ' ratio, lateral e', lateral $\mathrm{e}^{\prime} / \mathrm{a}$ ' ratio. With experience it is now recognized that there are several other aspects to the diastolic function and the parameters proliferated to the point of confusing the clinicians [Table-2]. The parameters and indices are getting evaluated leading to a large proliferation of various methods. In recent updated recommendations there was an effort to rationalize this and make it more practical and simple [8]. In these guidelines 4 variables and their cut-off values were defined. They are -1) Annular eO velocity (Septal$<7 \mathrm{~cm} / \mathrm{sec}$; lateral wall- $<10 \mathrm{~cm} / \mathrm{sec}) 2$ ) Average eO $>14$ $\mathrm{cm} / \mathrm{sec} 3$ ) LA maximum volume index $>34 \mathrm{ml} / \mathrm{m}^{2}$ and 4) TR velocity $2.8 \mathrm{~m} / \mathrm{sec}$.

Fig 3: Patient with normal diastolic function with E/A > 1, Short Decelaration Time (A) and patient with grade 1 diastolic dysfunction with Prolonged IVRT, dec-T, reduced $\mathrm{E}$ and $\mathrm{E} / \mathrm{A}$ ratio $<1$ (B).

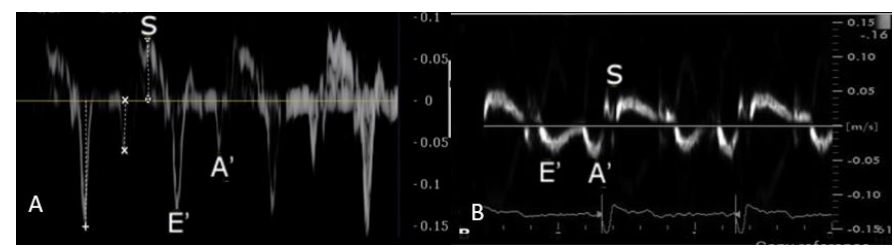

Fig 4: TDI of the lateral segment of the mitral annulus in a normal subject showing normal e' velocity and normal $\mathrm{e}^{\prime} / \mathrm{a}^{\prime}$ ratio (A) and TDI in heart failure patient showing reduced e' velocity as well as e'/a' suggestive of diastolic dysfunction (B).

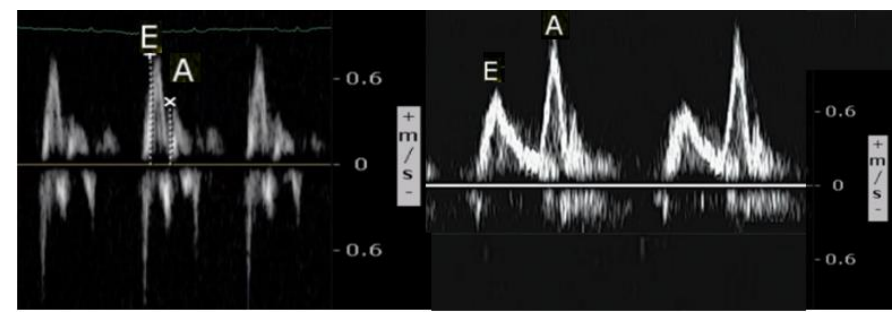

In recent years it is observed that longitudinal function and torsion (a twisting movement in systole due to myofiber bands attached to RV below the pulmonary valve and extends to LV where it is attached to the aorta) are of significance and affect the diastolic function. Parameters have been derived to assess these aspects as well which are being evaluated. Hemodynamic assessment of stroke volume, cardiac output and cardiac index can also be calculated by combined use of $2 \mathrm{D}$ echo and Doppler measurements.

Trans-esophageal echocardiogram (TEE) is semiinvasive with potential for injuries to the mouth, throat and esophagus and potential for laryngospasm, 
bronchospasm or air-way complications. It needs more training and more patient co-operation. TEE has better resolution of endocardial borders; but under-estimates the volumes and over estimates EF. Hence it cannot replace TTE in routine work-up. 3D TTE is superior to 2DTTE in accuracy and reproducibility; but can under estimate the volumes. It calls for a special transducer and some post processing and a bit more cumbersome than the 2D imaging. Data acquisition can be affected by quality of breath holding and regularity of heart beats during the acquisition [9].

\section{Invasive Catheterization methods}

This modality is sometimes used as an extension of coronary angiogram or cardiac catheterization for any other indication. It was popular as the gold -standard technique in the pre-echocardiographic days. Assessment of RWMA and mitral regurgitation used to be a routine after any coronary arteriography. There used to be automated software to give the LV volumes and EF. The endocardial borders can be detected by manual, semi-automated or automated methods at enddiastole and end-systole. Currently the invasive methods are used when timely adequate noninvasive information is not available or to look for any mechanical complications while evaluating the coronaries in a case of STEMI in shock. Concomitant measurement of hemodynamic parameters is an added advantage. Vascular issues, radiation exposure and use of contrast and catheter related artifacts are important limitations and the non-invasive techniques largely replaced the invasive modalities [10].

\section{Radionuclide Methods}

Ventricular function assessment was popular for many years for its reliability and high reproducibility especially when RWMA was present or when there were difficulties in echocardiographic imaging and in serial follow up of patients on cancer chemo-therapy. Its ability to accurately measure small changes in EF made it a choice method in research protocols. Non reliability in presence of arrhythmias, patient exposure to 6 to 7 $\mathrm{mSv}$ of ionizing radiation, contraindication in pregnancy and lactation, attenuation artifacts, and limited availability in the echocardiographic era made it a less preferred modality for ventricular function assessment (Fig 4). The EF assessment and RWMA were fairly comparable with cardiac MRI studies [11, 12].

The images are obtained with rest and stress phases in the evaluation of suspected or symptomatic CAD patients. The global and regional function can be evaluated accurately (Fig 6). Additionally, the ability to differentiate attenuation artifacts from true perfusion abnormalities and the simultaneous evaluation of both perfusion and function in the same study are the advantages of this modality. ECG gated SPECT-MPI was validated with CMR which showed high correlation. However due to its lower spatial resolution, it is primarily utilized for assessment of myocardial perfusion for CAD evaluation. Patient is exposed to 11 to $22 \mathrm{mSv}$ of ionizing radiation and is unsuitable for the pregnant women. Multiple ectopics and arrhythmias can affect the image quality [13]. Positron Emission Tomographic Myocardial Perfusion Imaging (PET-MPI): It is a superior alternative to SPECT with lesser ionizing radiation. Its excellent image quality and high diagnostic accuracy for assessment of Ischemic heart disease, evaluation of LV volumes and EF at rest and stress, myocardial flow assessment in the same study. However due to the need for gating the images can be affected by fast heart rates and arrhythmias [14].

\section{Cardiac CT}

The cross-sectional images over an entire cardiac cycle are acquired with ECG gating and reconstructed to assess LV function, characterization of myocardium, evaluation of coronaries and pulmonary vessels (Fig 7). By computer based summation of images LV volumes, ejection fraction and LV mass are calculated. These parameters had been compared with other modalities and validated. Though the temporal resolution of cardiac CT is inferior to other modalities, the EF calculated and the assessment of RWMA had excellent correlation with TTE $[15,16,17]$. LV assessment is generally performed as a con-commitant step to evaluation of the coronary anatomy. The best indication may be in patients with poor echo windows. The exposure to radiation and use of the contrast media are both disadvantages. Accuracy can be affected by too fast heart rates or by irregular rhythm. 
Fig 5: Single-photon Emission Computed Tomography Myocardial Perfusion Imaging (SPECT-MPI) in a severe LV dysfunction patient.

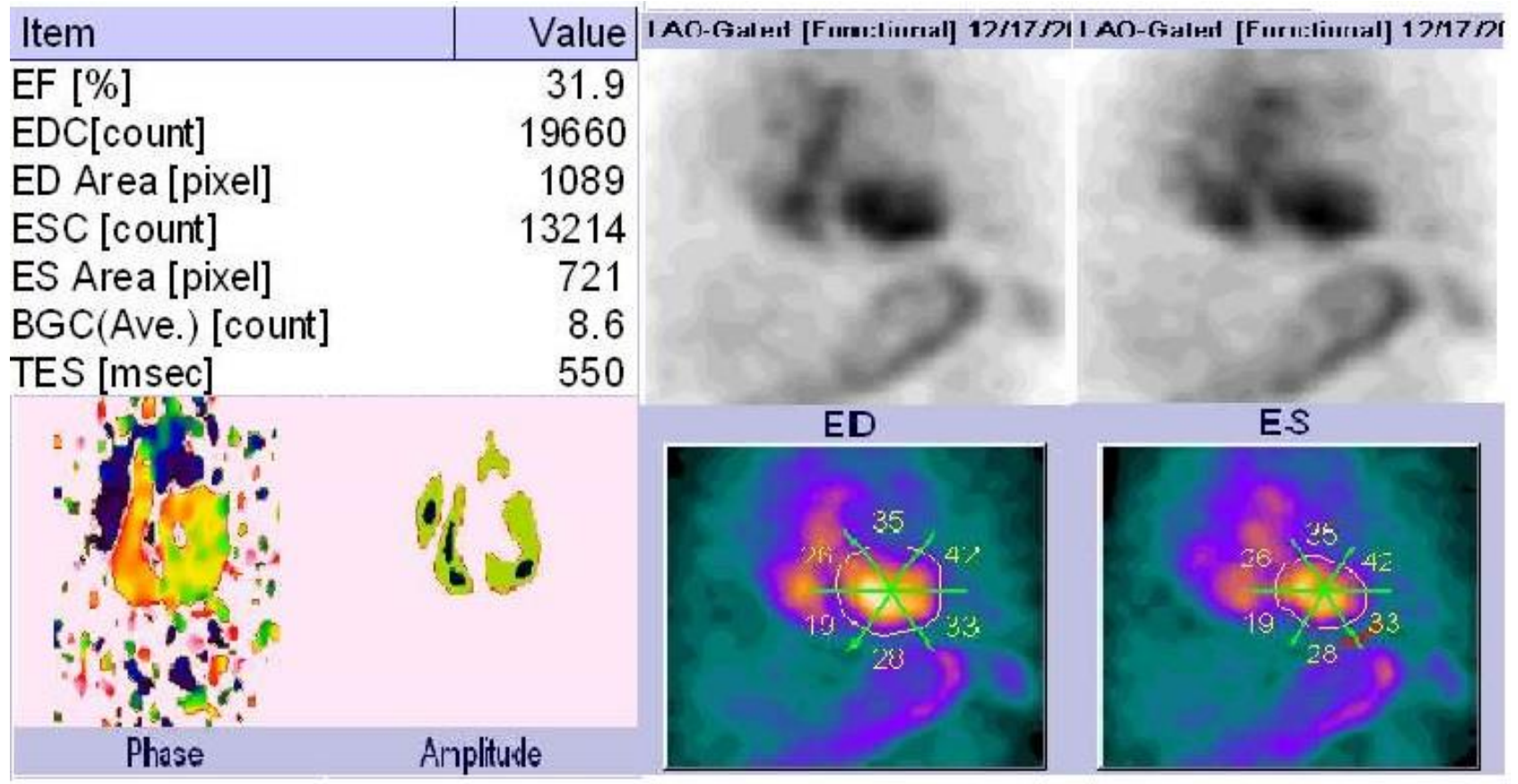

Fig 6 : Volumetric and bulles eye view for estimation of LV function
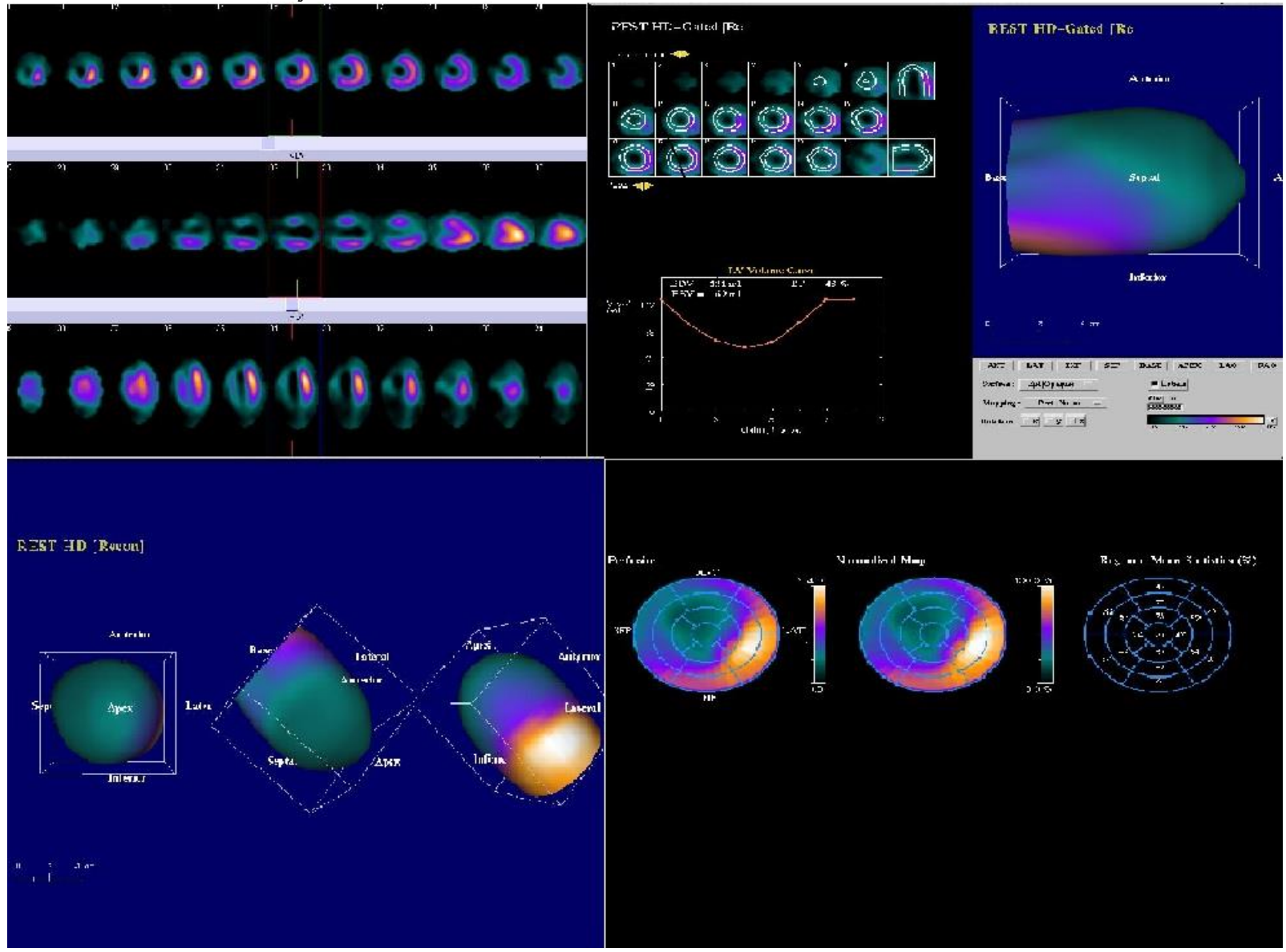
Fig 7: Cardiac CT for volume estimation of cardiac chambers.

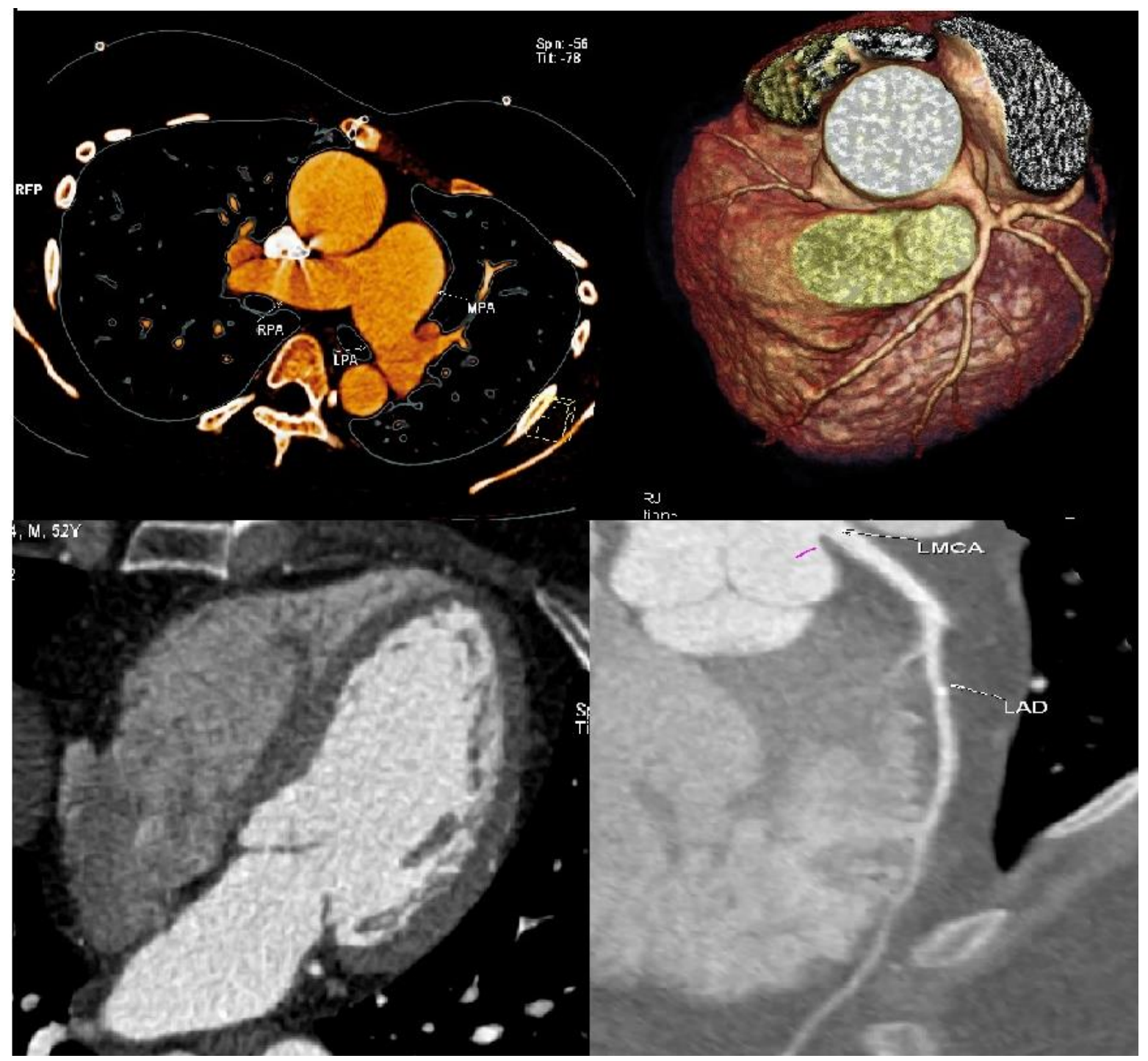

\section{Cardio-vascular MRI (CMR)}

In the current era it may be called the gold-standard for evaluation of LV function. There are no geometric assumptions to be made. The endocardial borders are precisely depicted without additional contrast use (Fig.8). If needed, it can be utilized to obtain hemodynamic data and myocardial contractility parameters. Inter- observer variability is the least compared to other modalities [18, 19]. The structural details like valves, endocardium, myocardium or the pericardium are better seen in cardiac MRI than in echocardiogram and hence best suited to the study of cardiomyopathies, aneurysms, heart failure evaluation, congenital heart disease, and valvular heart disease. Its ability to assess myocardial perfusion, viability and fibrosis and absence of radiation are 2 big advantages over other modalities like CT. Other advantages are nondependence on operator and non-interference from chest wall structure. It calls for avoidance of MRI noncompatible objects and more patient cooperation. Claustrophobia is a peculiar problem with some patients. Patient monitoring during the procedure is not optimal and it is unsuitable for very sick patients [20,21]. 
Fig 8 : Cardiac MRI for cardiac volumes measurement.

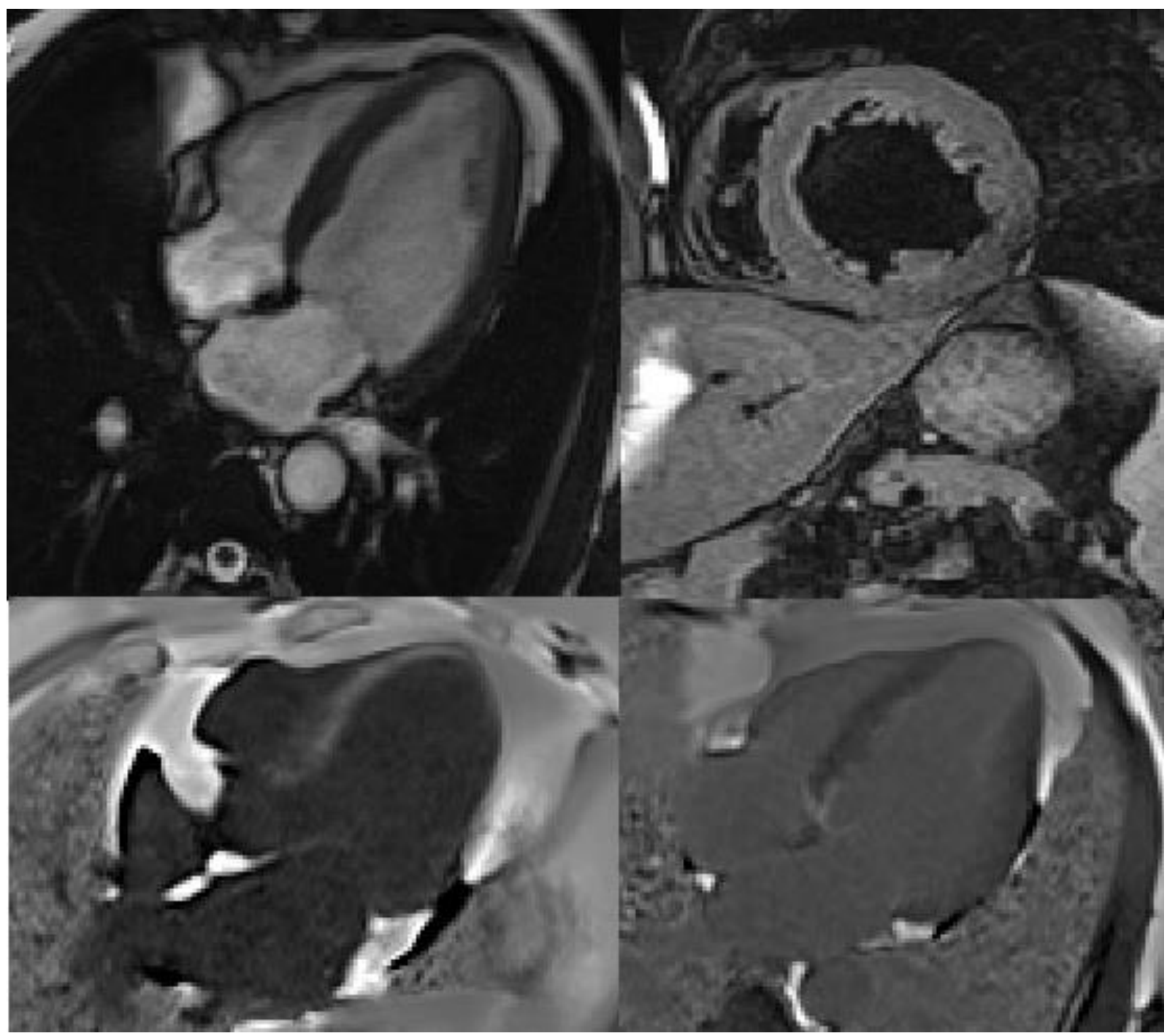

\section{SUMMARY AND CONCLUSIONS}

Management of many cardiac and medical conditions depends on assessment of LV function which is best accomplished by 2D TTE in daily practice. Several advantages and logistics make it the initial choice. Three-dimensional / volumetric methods are more accurate, but are cumbersome to be performed in every case. The measures of myocardial contractility are more sensitive, reliable and with lesser inter observer variability but their place in daily clinical practice is limited. Two-dimensional echocardiogram is the most favored modality due to its easy availability, low cost, portability, lack of radiation and non-invasive nature. Radionuclide studies, SPECT, cardiac CT and cardiac MRI have more specific indication to be used and assessment of LV function is often not the primary indication. Moreover, they are available only in a few centers. The ultimate choice of a modality depends on the information sought by the clinician and the availability of expertise. Additional cost, radiation and limited access are important concerns of these specialized modalities. The invasive methods are by and large relegated to academic exercise. 


\section{REFERENCES}

1. Van Royen N, Jaffe CC, Krumholz HM et al. Comparison and reproducibility of visual echocardiographic and quantitative radionuclide left ventricular ejection fractions. Am J Cardiol 1996; 77: 843

2. Amico AF, Lichtenberg GS, Reisner SA et al. Superiority of visual versus computerized echocardiographic estimation of radionuclide left ventricular ejection fraction. Am Heart J 1989; 118: 1259.

3. .Mueller X, Stauffer JC, Jaussi A et al. Subjective visual echocardiographic estimate of left ventricular ejection fraction as an alternative to conventional echocardiographic methods: comparison with contrast angiography. Clin Cardiol 1991; 14: 898.

4. Malm S, Frigstad S, Sagberg E et al. Accurate and reproducible measurement of left ventricular volume and ejection fraction by contrast echocardiography: a comparison with magnetic resonance imaging. J Am Coll Cardiol 2004: 44; 1030.

5. Lang RM, Badano LP, Mor-Avi $\mathrm{V}$ et al. Recommendations for cardiac chamber quantification by echocardiography in adults: an update from the American society of echocardiography and the European Association of Cardiovascular Imaging. J Am Soc Echocardiogr 2015: $28: 1$

6. Bargiggia GS, Bertucci $\mathrm{C}$, Recusani $\mathrm{F}$ et al. A new method for estimating left ventricular $\mathrm{dP} / \mathrm{dt}$ by continuous wave Doppler echocardiography. Validation studies at cardiac catheterization. Circulation 1989; 80: 1287.

7. Thavendiranathan P, Poulin F, Lim KD et al. Use of myocardial strain imaging by echocardiography for early detection of cardiotoxicity in patients during or after cancer chemotherapy: a systematic review. J Am Coll Cardiol 2014; 63: 2751.
8. Naguesh SF, Smiseth OA, Appleton CP et al. Recommendations for the evaluation of the left ventricular diastolic function by echocardiography: An update from the American society of Echocardiography and the European Association of cardiovascular Imaging. J Am Soc Echocardiogr 2016; 29: 277.

9. Dorosz JL, Lezotte DC, Weitzenkamp DA et al. Performance of 3-dimensional echocardiography in measuring left ventricular volumes and ejection fraction: a systematic review and meta-analysis Am Coll Cardiol 2012; 59: 1799.

10. Giglotti OS, Babb JD, Dieter RS et al. Optimal use of left ventriculography at the time of cardiac catheterization: a consensus statement from the society for Cardiovascular angiography and interventions. Catheter Cardiovascular Interv 2015; 85: 181.

11. van Royen N, Jaffe CC, Krumholz HM, et al. Comparison and reproducibility of visual echocardiographic and quantitative radionuclide left ventricular ejection fractions. Am J Cardiol 1996; $77: 843$

12. Nicholos KJ, Van Tosh A, Wang et al. Validation of gated blood pool SPECT regional left ventricular function measurements. J Nucl Med 2009; 50: 53.

13. Abidov A, Germano G, Hachamovitch R et al. Gated SPECT in assessment of regional and global left ventricular function: an update. J Nucl Cardiol 2013; 20: 1118.

14. Miller TR, Wallis JW, Landy BR et al. Measurement of global and regional left ventricular function by cardiac PET.J Nucl Med 1994; 35: 999.

15. Schepis T, Gaemperli O, Koepfli et al. Comparison of 64 slice CT with gated SPECT for evaluation of left ventricular function. J Nucl Med 2006; 47: 1288.

16. Butler J, Shapiro MD, Jassal DS et al. Comparison of multidetector computed tomography and two- 
dimensional transthoracic echocardiography for left ventricular assessment in patients with heart failure. Am J Cardiol 2007; 99: 247.

17. Wu YW, Tadamura E, Yamamuro $M$ et al. Estimation of global and regional cardiac function using 64-slice computed tomography: a comparison study with echocardiography gated SPECT and cardiovascular magnetic resonance. Int J Cardiol 2008; 128: 69 .

18. Walsh TF, Hundley WG. Assessment of ventricular function with cardiovascular magnetic resonance. Cardiol Clin 2007; 25:15.

19. Lotan CS, Cranney GB, Bouchard A et al. The value of cine nuclear magnetic resonance imaging for assessing regional ventricular function. J Am Coll Cardiol 1989; 14: 1721.
20. Sourides BE, Theofilogiannakos EK, Theofilogiannakos $\mathrm{G}$ et al. Clinical experience from 1000 consecutive cardiovascular MRI cases at a tertiary referral medical center. Hellenic J Cardiol 2007; 48: 192.

21. Valle-Munoz A, Estomell-Erill J, Soriano-Navarro $\mathrm{CJ}$ et al. Late Gadolinium enhancementcardiovascular magnetic resonance identifies coronary artery disease as etiology of left ventricular dysfunction in acute new onset congestive heart failure. Eur J Echocardiogr 2009; 10; 968 